DIW BERLIN

Discussion

Papers

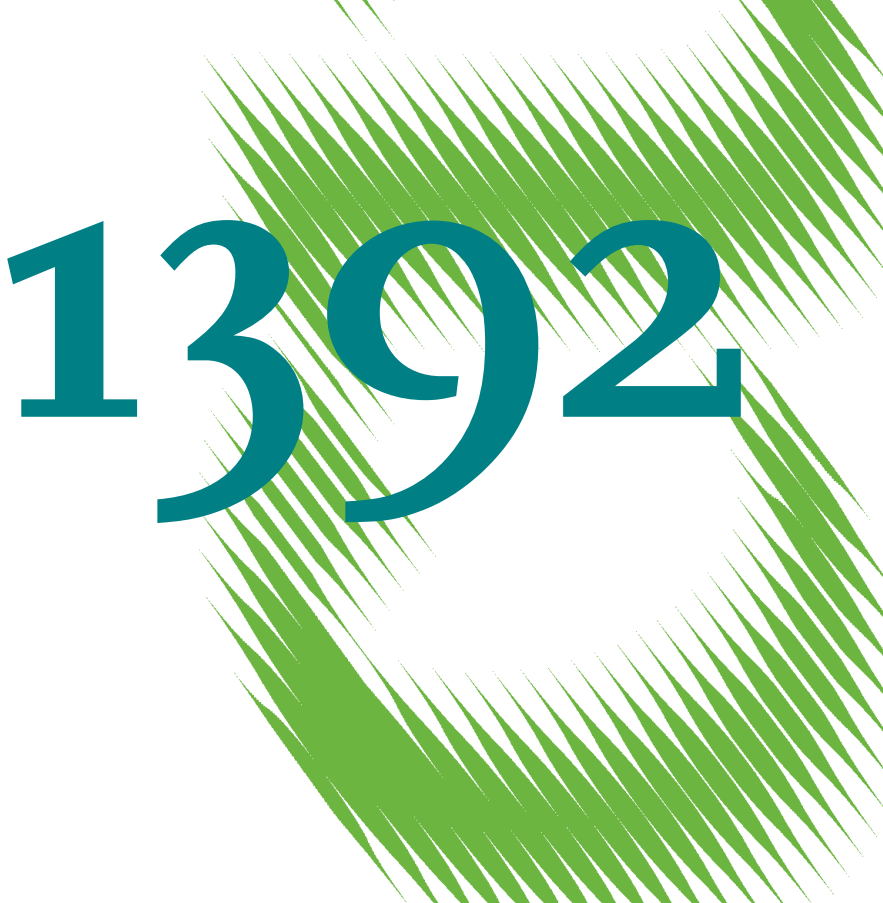

The Role of Visible Wealth for Deprivation 
Opinions expressed in this paper are those of the author(s) and do not necessarily reflect views of the institute.

IMPRESSUM

(C) DIW Berlin, 2014

DIW Berlin

German Institute for Economic Research

Mohrenstr. 58

10117 Berlin

Tel. +49 (30) $89789-0$

Fax +49 (30) $89789-200$

http://www.diw.de

ISSN electronic edition 1619-4535

Papers can be downloaded free of charge from the DIW Berlin website:

http://www.diw.de/discussionpapers

Discussion Papers of DIW Berlin are indexed in RePEc and SSRN:

http://ideas.repec.org/s/diw/diwwpp.html

http://www.ssrn.com/link/DIW-Berlin-German-Inst-Econ-Res.html 


\title{
The Role of Visible Wealth for Deprivation
}

\section{Veronika Bertram-Hümmer* Ghassan Baliki ${ }^{\dagger}$}

June 16, 2014

\begin{abstract}
Motivated by the lack of literature linking actual to perceived relative deprivation, this paper assesses the role of visibility in the deprivation of goods and assets vis-à-vis income behind perceptions of relative deprivation. We rely on household survey data that includes unique information on reported perceived deprivation with a pre-specified reference group, namely others in the town or village. Based on a large number of asset and consumption items, we create an index of visible wealth by aggregating visible goods and assets using principal component weights. We find that relative deprivation in visible wealth has a ten percentage point higher explanatory power for reporting a high level of perceived deprivation than that of deprivation in income. The effect is robust under various sensitivity checks and for a number of controls. The finding sheds light on the importance of the visibility of the objects of comparison for an individual's assessment of his relative economic situation and proposes that future research should not solely rely on income-based deprivation measures.
\end{abstract}

Keywords: relative deprivation; visible wealth; income; comparison group.

JEL Classification Numbers: C23, C25, D31, I31, P3.

\footnotetext{
${ }^{*}$ German Institute for Economic Research (DIW Berlin), Mohrenstrasse 58, 10117 Berlin, Germany. E-mail: vhuemmer@diw.de. Tel.: +49 30 89789-615. Fax: +49 30 89789-108. The author thanks DIW Berlin for funding.

${ }^{\dagger}$ German Institute for Economic Research (DIW Berlin), Mohrenstrasse 58, 10117 Berlin, Germany. E-mail: gbaliki@diw.de Tel.: +49 30 89789-346. Fax: +49 30 89789-200. The author thanks TAMNEAC for funding. The authors would like to thank for the constructive comments from Christopher Boyce, Andrew Clark, Conchita D'Ambrosio, Damir Esenaliev, Nathan Fiala, Guillermina Jasso, Adam Lederer, Friederike Lenel, Bakhrom Mirkasimov, Kati Schindler and Susan Steiner.
} 


\section{Introduction}

The notion that happiness and well-being are not just only dependent on an individual's own economic standing, but also on their relationship to others has been strongly established within the social science literature (Easterlin 1995, 2001, Mc Bride 2010, Alpizar 2005, Kingdon and Knight 2007, D'Ambrosio and Frick 2007, among others). Economists have voluminously examined the effects of relative deprivation (see below) on economic behavior and decision-making. They find strong evidence for direct repercussions on every day decisions, such as consumption (Kuhn 2011, Linssen 2011) and taking health risks (Eibner and Evans 2005, Deaton 2001). Moreover, relative deprivation is found to drive more potent decisions in life, such as the use of violence (Birrell 1972 , Macours 2011) and migration (Stark 1984, 1991, Bhandari 2004). At the same time, this vast literature has failed to address questions related to the constituents of relative deprivation. These constituents include mainly the "object of comparison" and the "reference group". Most empirical studies relating relative deprivation to happiness do not address these issues explicitly, and only give various arbitrary assignments to both the group of reference and the object of comparison (Luttmer 2005, Ferrer-i-Carbonell 2005, Kingdon and Knight 2007, Klasen 2000, among others).

The term relative deprivation was initially coined by Runciman (1966), where a person $A$ is considered relatively deprived of an object $X$ when (1) $A$ does not have $X$ and wants it, and sees it as feasible that he should have it, and (2) sees some other person or persons $G$ with $X\}^{1}(1)$ and (2) reflect the deprivation and the relativity criteria respectively. Hence, by definition, in order for both criteria to be satisfied, an essential condition is required: object $X$ and a reference group $G$ must be seen by $A$. In the following, we call this the visibility condition for relative deprivation.

The main choice of object $X$ in empirical studies is income due to its wide availability in survey data, and since it is considered to be proportional to other dimensions of economic well-being (e.g. Deaton 2001, Kingdon and Knight 2007, D'Ambrosio and Frick 2012). But does income satisfy the full conditions to be used as a measure of relative deprivation? Despite possible inaccuracies in the measurement of income due to the underreporting by the rich and the miscalculation by the self-employed and the poor (Biemer et al. 2011, Van Praag et al. 1983), income may still qualify for the assessment of absolute deprivation since it is privately known. Yet for the calculation of relative deprivation measures, income may not be as valuable since the information on earnings of all the comparison group members must be available a priori to all individuals. Realistically, this information is difficult to obtain given that income is neither easily observable nor necessarily visible. Moreover, income and total earnings neglect the disaggregation of a household's decision into expenditures and savings, which is

\footnotetext{
${ }^{1}$ In the following, the term "deprivation" is used equivalently to "relative deprivation" throughout the rest of the paper.
} 
vital for understanding different mechanisms of relative deprivation. In order to overcome the limitations of income measures, other studies use consumption, positional goods or assets values as objects of comparison, which may comprise better indices in analyzing relative deprivation (e.g. Klasen 2000, Fafchamps and Shilpi 2008, Ravallion and Loshkin 2008, Linssen 2011). However, these studies rely heavily on aggregates without differentiating between the observable and unobservable elements of their indices and hence do not account directly for the visibility condition.

Another shortcoming in the empirical literature is the identification of the comparison group $G$. Few studies explicitly ask respondents with whom they are comparing (Knight et al. 2009, Clark and Senik 2010). Knight et al. (2009) find that people in the immediate vicinity - namely the neighbors and villagers - are the most frequently chosen comparators in rural China. Clark and Senik (2010), on the other hand, find that colleagues are the most mentioned group of reference when comparing income in Europe. Without available information on the group of comparison, a common default choice is "all citizens of a country or a region" (e.g. Easterlin 1995, Deaton 2010, Klasen 2000, Grimm et al. 2002, Bhandari 2004). This is generally based on strong assumptions given that it is simply hard to believe that a farmer in the countryside would compare himself with a businessman in the city whom he most probably has never seen.

To the best of our knowledge, no study yet has used an index to measure relative deprivation, consisting of visible items, and only few determine the reference group. Moreover, and to our surprise, we could not find any study that compares and assesses the effectiveness and reliability of various indices for measuring relative deprivation. Motivated by Runciman's pioneering theory and the empirical gap in the analysis of the relative deprivation indices, this paper has two aims: (i) to introduce a measure of visible wealth as an object for relative deprivation which is constructed to meet the visibility condition as precisely as possible with household data, and (ii) to evaluate its performance against income to determine the driving elements behind true relative deprivation.

In order to accomplish those two aims, we use data from a socio-economic household survey in Kyrgyzstan in 2011. This survey dataset is of special significance because it includes unique information on an individual's perceived level of relative deprivation. Perceived relative deprivation serves as our proxy for the true level of relative deprivation and will be the main dependent variable of analysis. Moreover, the question on perceived relative deprivation clearly specifies the comparison group for the respondents as "other people in the town or village". This advantage allows us to steer away from any assumptions regarding the assignment of a relevant comparison group. Further, it facilitates matching the aggregation level of the calculated deprivation measures with reported deprivation, given that we can easily generate the indices for both income and visible wealth at the town and village levels too. For the creation of the visible 
wealth index, we identify and select a range of visible consumption and asset items in different wealth dimensions (housing, transportation, livestock, durables and commodities). We generate corresponding weights for each dimension separately using principal component analysis (PCA) and then aggregate them into a unitary composite index. By testing the separate and joint effects of the relative deprivation indices in income and visible wealth on perceived relative deprivation, we find that the visible wealth index has a 10 percentage point higher explanatory power than income. The results are robust under different specifications of the model, and hold strongly with the inclusion of various controls and under numerous sensitivity checks. These findings shed light on the importance of visibility in relative deprivation measures and urge future research to not just rely on income when analyzing the effects of relative deprivation on well-being and behavior.

The following section introduces the testing strategy and explains our empirical model. Section 3 explains the data and how the visible wealth index and the actual deprivation mea-

sures are calculated. In section 4 , descriptive and estimation results are discussed, followed by different robustness and sensitivity checks. Section 5 concludes.

\section{Testing Strategy}

Building on Runciman's work (1966), our testing strategy is structured to compare the influence between observable and non-observable relative deprivation indicators on the levels of perceived deprivation. In order to do establish this structure, we first assume that the utility of every individual depends only on their economic deprivation position to others, without the inclusion of the absolute levels. Hence, let the utility function of an individual $i$ be standardized and depend negatively on the level of relative deprivation $D_{i c}^{*}$, then

$$
U_{i}=1-D_{i c}^{*}
$$

with $D_{i c}^{*} \in[0,1]$ being the normalized measure of the true feeling of relative deprivation of individual $i$ in comparison group $c$. This simply implies that the most (least) deprived individual within his comparison group has a utility equal to zero (one). It is important to note that here $D_{i c}^{*}$ does not reflect the actual levels of relative deprivation, but rather the feeling of relative deprivation.

In order to make a clear distinction between true feelings of relative deprivation $D_{i c}^{*}$ and actual levels of relative deprivation $D_{i c}^{a}$, imagine a group $G$ with 3 individuals $\left(i_{1}, i_{2}\right.$, and $\left.i_{3}\right)$. All three individuals are fully informative, rational, and have identical psychological and demographic traits and characteristics. $i_{1}, i_{2}$, and $i_{3}$ own 1,2 , and 3 cows respectively. Let their utility only depend on the number of cows they own relative to the others. Then, the actual relative deprivation 
in cows for $i_{1}$ for instance, is 2 compared to $i_{3}$ and 1 compared to $i_{2}$, for $i_{2}$ it is 1 compared to $i_{3}$, while the actual relative deprivation for $i_{3}$ is 0 . Given that all individuals are identical, rational, and fully informative, then their true feelings of relative deprivation are equal to the actual deprivation. In other words, $i_{1}$ knows he is the most deprived and feels this way, while $i_{3}$ knows he is the least deprived (or not deprived) and feels this way. However, the true feelings of relative deprivation under any other assumptions would not necessary be equal to the actual levels of relative deprivation. For example in the case without full information, $i_{2}$ might think that $i_{1}$ is secretly hiding another two cows in the barn (which is not the case), then he feels that he is most deprived although in reality he is not, and therefore his utility will be also equal to 0 . Thus, the true feeling of deprivation $D_{i c}^{*}$ might not necessarily coincide with the actual deprivation $D_{i c}^{a}$. The relationship can be shown as follows:

$$
D_{i c}^{*}=\beta D_{i c}^{a}+\sum_{k}^{K} \gamma_{k} x_{k i}+\sum_{l}^{L} \delta_{l} w_{l c}
$$

where $x_{i k}$ is the set of $K$ individual-specific factors and $w_{l c}$ the set of $L$ comparison group-specific factors that may influence the sense of relative deprivation independently from the economic elements. These can include individual characteristics (age, gender, character traits etc.), general levels of satisfaction in life, as well as values and norms within the comparison group. In order to account for the visibility condition in the computation of actual relative deprivation, let $D_{i c}^{a}$ be mainly comprised of two mutually exclusive constituents, the visible component $D_{i c}^{v}$ and the invisible $D_{i c}^{n}$ :

$$
D_{i c}^{a}=\theta_{1} D_{i c}^{v}+\theta_{2} D_{i c}^{n}
$$

where $\theta_{1}$ and $\theta_{1}$ signify the weights that each individual assigns to the two components in assessing his relative position to others, such as $0<\theta_{1}+\theta_{2} \leq 1$. We aim to test the magnitude of $\theta_{1}$ and $\theta_{2}$ in order to be able to assess the role of visibility in determining the factors in play behind true feelings of relative deprivation.

Using empirical data imposes two challenges: neither the true feelings of relative deprivation $D_{i c}^{*}$ can be directly measured, nor the explicit differentiation between visible and invisible items can be clear-cut observed. Therefore, in order to overcome those two challenges, we need to find proxies for $D_{i c}^{*}, D_{i c}^{v}$ and $D_{i c}^{n}$. First, in order to capture the closest representation of the true feelings of relative deprivation, we use reported levels of perceived relative deprivation $D_{i c}$ as a proxy, with

$$
D_{i c}=\tau \Longleftrightarrow \kappa_{\tau} \leq D_{i c}^{*}<\kappa_{\tau+1} \text {. }
$$

Reported perceived relative deprivation $D_{i c}$ is an 11-point Likert scale variable, where $\tau$ stands for the choice category (0-10), and $\kappa$ for the unknown threshold parameters on different levels of truly felt deprivation $D_{i c}^{*}$ that are represented by the choice categories. Thus, $D_{i c}$ is a positive 
monotonic transformation of the underlying latent variable of truly felt deprivation $D_{i c}^{*}$ (see Maddala 1986, Greene 2010).

Second, due to the omission of explicit information on visibility of the objects of comparison in empirical survey data, we use relative deprivation in visible wealth $D V_{i c}$ and in income $D I_{i c}$ as proxies for $D_{i c}^{v}$ and $D_{i c}^{n}$ respectively, then

$$
\begin{aligned}
& D_{i c}^{v}=\theta_{1} D V_{i c}+\epsilon_{1 i}, \\
& D_{i c}^{n}=\theta_{2} D I_{i c}+\epsilon_{2 i} .
\end{aligned}
$$

Based on the theoretical structure in equations 2, 3, and 4, and the empirical proxies shown in equations 5 and 6, our empirical estimation strategy is as follows:

$$
D_{i c}=\alpha+\beta_{1} D V_{i c}+\beta_{2} D I_{i c}+\sum_{k}^{K} \gamma_{k} x_{k i}+\sum_{l}^{L} \delta_{l} w_{l c}+\varepsilon_{i}
$$

with the individual specific factors $x_{i k}$ include sex, age, marriage, being a native, education, the general level of satisfaction and the so-called Big-5 character traits which reflect a person's openness, conscientiousness, extroversion, agreeableness and neuroticism (O'Brien and De Longis, 1996). The group-specific characteristics $w_{l c}$ influencing perceived deprivation distinguish between regional differences and between rural and urban livelihoods.

In theory, we predict that only visible indicators have a significant role on the levels of perceived relative deprivation. Yet, given the implausibility in observational data to distinguish clearly between $D V_{i c}$ and $D I_{i c}$, we hypothetically test for $\beta_{1}>\beta_{2} \geq 0$. If we are able not to reject this hypothesis, then we can confidentially conclude that visibility is an important aspect in measuring relative deprivation.

\section{Measuring Visible Wealth and Deprivation}

\subsection{Data}

We rely on the "Life in Kyrgyzstan" (LIK) panel, a comprehensive socio-economic household survey, as it includes unique information on subjective deprivation in 120 towns and villages. The survey is representative for the population in Kyrgyzstan relying on a stratified two-stage random sampling that was based on the 2009 Census (Brück et al. 2014).2 We use the second LIK wave,

\footnotetext{
${ }^{2}$ The survey was conducted by the German Institute for Economic Research (DIW Berlin) in cooperation with local partners in Bishkek. The questionnaires in Kyrgyz, Russian and English can be accessed at the project website: http://www.diw.de/kyrgyzstan.
} 
from 2011, as it introduces the question on perceived deprivation. Attrition between the first wave in 2010 (with an original sample size of 3,000 households) and the follow-up is low (4.56\%). The attrition households are mostly urban dwellers who are slightly, but not significantly, poorer than the households remaining in the second wave. For the analysis, we pool the heads of 2,808 households with valid information on perceived deprivation, income, consumption and asset items 3 The non-response within the survey is generally low, with few missing values in perceived deprivation (less than $2 \%$ ) and even fewer missing values in the economic indicators (less than 1\%).

The key dependent variable and our benchmark for the comparison between visible and invisible deprivation is the question on self-assessed economic deprivation: "How would you rate your household's current economic situation compared with other people in your town or village?' or completely satisfied (10) with their situation relative to others in their town or village. People who think they are below the average give themselves a measure below five, those who think they are better off, rate above. The question has unique features that facilitate an in-depth analysis of the determinants of deprivation. First, the respondents reveal their perceived deprivation. This kind of subjective information on deprivation comes presumably closer to the underlying feeling of deprivation than any calculated deprivation measure. Second, the question defines the comparison group such that there is no need for making any artificial assumption about with whom people compare. In addition, the specified comparison group, namely other people in the town or village, presumably fulfills the visibility condition of deprivation. To make the variable comparable to the calculated measures of deprivation (see below, section 3.3), the variable is inverted, with zero standing for "not deprived at all" and ten for "completely deprived". The categories between six and ten reflect that a person perceives himself as deprived.

For the calculation of deprivation in income, we use information on 22 different income sources of all household members, including monthly wages and salaries, social transfers, material aids, and income from household enterprises, from property and other income sources. Information on a large range of asset and consumption items serves as the pool for the selection into the indicator of deprivation in visible wealth (see below, section 3.2). This includes the ownership of 40 different assets and the respective monetary values for 14 of them, as well as the monetary values for 21 non-food consumption items. Besides information on numerous individual characteristics of the respondents, we exploit information on general satisfaction in life and the so-called Big 5 character traits. The character traits are only available for a part of the respondents as they were elicited only in the 2012 LIK wave, when some of the respondents in 2011 were not present during the

\footnotetext{
${ }^{3}$ If the head of the household was not available during the interview, we use information of the spouse or the most senior household member who responded.

${ }^{4}$ Both the Kyrgyz and the Russian translation of the question (as asked in the interviews) reflect the respondent's perceived deprivation within the town or village.
} 
interview or dropped out (211 out of 2808).

\subsection{Measuring Visible Wealth}

To compare the notion of visible wealth with income, a measure for visible wealth needs to be created. This implies several challenges. First, visible wealth is manifested in numerous assets and consumption goods. The visibility of an item is not a clear-cut feature. Each of the items might meet the visibility criteria in some circumstances, while in others it does not. Furthermore, the items are usually measured in different scales, as for some, survey respondents are able to report the monetary values (continuous scale), while for others, only information on the ownership (binary or count scale) can be recalled.

From the pool of asset and consumption items in the LIK data, we identify 38 asset and consumption items (see table 1) that are usually observable by others within the village or town. To deal with the different scales, we aggregate first the selected variables within each of the dimensions, housing, transport, livestock, durables and consumption, before calculating deprivation and creating a composite indicator $5^{5}$

For the aggregation of the variables within each dimension, we use weights derived from Principal Component Analysis (PCA), as they retain most of the variance of the original variables (Kolenikov and Angeles 2004; 2009). The concept of PCA is based on the idea that the $N$ visible items $v$ of household $i$ are connected by underlying components $C$ as follows:

$$
\begin{array}{r}
v_{1 i}=\alpha_{11} C_{1 i}+\alpha_{12} C_{2 i}++\alpha_{1 N} C_{N i}, \\
\ldots \\
v_{N i}=\alpha_{N 1} C_{1 i}+\alpha_{N 2} C_{2 i}++\alpha_{N N} C_{N i},
\end{array}
$$

with $\alpha_{n}$ as the eigenvectors. As only the visible goods $v$ and not the components $C$ are observed, these equations are inverted to find orthogonal linear combinations that retain a large part of the variance of the original variables. The first principal component consists of the sum of the items $v$ multiplied with the PCA weights $\beta$ :

$$
C_{1 i}=\beta_{11} v_{1 i}+\beta_{12} v_{2 i}++\beta_{1 N} v_{N i}
$$

Accordingly, the magnitude of each weight depends on the extent of information that the item provides about the other items. For example, if expenditures in eating-out is highly correlated

\footnotetext{
${ }^{5}$ Housing, means of transport and consumption items are assessed in monetary units (continuous variable), and durables in the quantities owned (count variable). For comparability, the livestock quantities are transferred into livestock equivalent units. We use the FAO (1995) equivalence scales (horse 1, cow 1, sheep 0.15, goat 0.15, pig $0.15)$.
} 
with other dimensions of visible consumption, such as the purchase of clothing, then the weight for eating-out consumption in the visible wealth index becomes large and positive. Within each dimension, we conduct principal component analysis on the selected variables. In each of the five dimensions, we find the weights from the first component to be highly relevant for the outcome indicator of perceived deprivation $\sqrt[6]{6}$ Hence, the weights from the first component are taken when aggregating the selected variables (see screeplots in figure 1).

\subsection{Calculating Deprivation}

We use Yitzhaki (1979) deprivation measures for calculating deprivation in visible wealth and in income. Compared to other measures in the literature, which mainly rely on mean-based indicators (e.g. Luttmer 2005, Bossert et al. 2013), the Yitzhaki measure meets the relativity conditions of Runciman for individuals in all parts of the distribution and allows us to stay away from any exogenous threshold to determine deprivation. The level of the Yitzhaki measure of deprivation of individual $i$ is calculated as follows:

$$
D_{i c}^{y}=\sum_{j=i ; c_{i}(y)}^{N-1}\left(1-p\left(y_{i}\right)\right)\left(y_{j+1}-y_{i}\right)=\frac{1}{N} \sum_{j=i ; c_{i}(y)}^{N-1}\left(y_{j+1}-y_{i}\right)
$$

with wealth units $y_{1}, y_{2}, \ldots, y_{n}$ such that $y_{1} \leq y_{2} \leq \ldots \leq y_{n}, p(y)=\operatorname{prob}\left(y_{i} \leq y_{j}\right)$ and comparison group $c_{i}$ such that $c_{i}(y)=\left\{j \in N \mid y_{j}>y_{i}\right\}$. In other words, the level of deprivation of person $i$ is calculated as the sum of differences between i's wealth and the wealth of all others above, divided by the total number of individuals $N$ in the comparison group $c$. This implies that a person only compares himself with those in the comparison group who are better-off.

The person with the highest wealth among all individuals in a comparison group has a value of $D_{i c}^{y}=0$. We calculate Yitzhaki's measures of deprivation for income $D_{i c}^{n}$ and for each of the different dimensions of visible wealth. All measures are normalized to a range from zero to one to make them comparable. Based on the Yitzhaki measures in the different dimensions, a composite indicator of deprivation in visible wealth $D_{i c}^{v}$ is calculated giving an equal weight for each dimension. This linear aggregation implies that a person who has less in one dimension can compensate in the other dimensions, as suggested by Permanyer (2014). The separate calculation of deprivation within each dimension of visible wealth implies two further assumptions. First, comparisons are made within the dimensions, such that individuals compare their dwellings with the dwellings of others. Second, the deprivation of visible wealth of a household includes only dimensions with some variation within the town or village. For example, for households in the

\footnotetext{
${ }^{6}$ Higher principal components did not show significant correlations and, in some cases, not the expected negative direction of the relationship with perceived deprivation. Therefore we did not use higher components for the analysis.
} 
city without any livestock in the comparison group, the livestock dimension is not considered in the indicator for deprivation in visible wealth.

We choose the other sampled households in the town or village in the LIK survey as the comparison group in the calculation of deprivation. In the survey, 25 households were randomly selected in each primary sampling unit. Hence, the comparison group consists of 23 to 24 households in the town or village who were available in the 2011 interview and did not drop out after the first year of data collection. Although, we are aware of the fact that the sample is not representative at this level, the other sampled households within the town or village seem to be the most adequate comparison group for the following reasons. Other households in the town or village are within reach of the respondent. As such, they come closest both to Runciman's (1966) definition and to the specified comparison group in the question on perceived deprivation. As a check for the adequate comparison group, we calculated deprivation measures at the regional and the national level. We find the relationship between reported deprivation and calculated deprivation on the regional or national level is significantly less pronounced than on the town or village level which supports our choice of the comparison group.

\section{Deprivation in Visible Wealth and Income Compared}

\subsection{Descriptives}

One quarter of the respondents feels deprived and choses a category higher than the middle (see figure 22. This means that most individuals in our sample do not feel deprived. The average level of deprivation $\mu$ in visible wealth is 0.49 . This is clearly the highest in comparison to deprivation in income $(\mu=0.42)$ and perceived deprivation $(\mu=4)$ (see table 2). At the same time, deprivation in visible wealth is much less volatile than deprivation in income and perceived deprivation. The coefficient of variation $(c v)]^{7}$ is 0.41 for deprivation in visible wealth, while it is 0.69 for deprivation in income and 0.53 for perceived deprivation. Comparing the correlation $\rho$ between perceived deprivation and the absolute deprivation measures, perceived deprivation is significantly higher correlated with deprivation in visible wealth $(\rho=0.33)$ than with deprivation income $(\rho=0.24)$.

\subsection{Estimation Results}

We estimate deprivation in visible wealth and in income on perceived deprivation as specified in equation 7 (see table 3). As the 11-point Likert scale dependent variable can be considered to be continuous, initially a simple OLS estimation is conducted (columns 1-2). We run separate estimations with the subsample that reported their level of perceived deprivation in 2011 and

\footnotetext{
${ }^{7}$ The $c v$ is defined as the ratio of the standard deviation and the mean
} 
on their individual-specific character traits in 2012 (column 1) and with the full 2011 sample (column 2). We find the explanatory power of deprivation in visible wealth to be significantly larger than that of deprivation in income in the joint estimation. An ordered logit specification does not change this result (column 3). When separately estimated, both deprivation in visible wealth and in income affect perceived deprivation with large positive and significant coefficients (columns 4-5). Other prominent factors that explain perceived deprivation include being generally dissatisfied with life and living in an urban area. Being higher educated and conscientious has a small, but significant negative effect on perceived deprivation.

Since the magnitude of the coefficients is difficult to interpret, we further calculate the predicted probabilities of reported perceived deprivation (categories 6-10) based on the ordered logit estimation (see figure 3). A person with highest deprivation in visible wealth, $D_{i c}^{v}=1$, (and all other variables at the mean), has a probability of $23 \%$ for feeling deprived, while the probability is only $13 \%$ for a person with highest deprivation in income $D_{i c}^{n}=1$. In other words, highest deprivation in visible wealth predicts perceived deprivation with about 10 percentage points higher probability than deprivation in income. We cannot reject the hypothesis $\beta_{1}>\beta_{2} \geq 0$. A person's feeling of deprivation is more likely to be explained by high levels of deprivation in visible wealth than by his deprivation in income.

\subsection{Robustness and Sensitivity Checks}

The finding on the importance of deprivation in visible wealth relies on a number of assumptions related to the way the indicator of visible wealth and the measures of deprivation are calculated, how the question on perceived deprivation is understood by the respondents and their willingness to reveal their true feelings of deprivation. The result might be driven by one or several of these assumptions. Furthermore, it might be biased by the outliers that are particularly prevalent in the income data. To address these concerns, we conduct a range of robustness and sensitivity checks.

One major issue relates to the creation of the visible wealth indicator. We start with a sensitivity check on how the different dimensions of visible deprivation affect perceived deprivation. If only one of the dimensions turns out to be important, this would indicate deprivation is merely influenced by inequalities in this dimension rather than in visible wealth. We estimate the effect of each dimension on perceived deprivation separately and compare them with deprivation in income (see table 4). In the joint regression, the effect on perceived deprivation is more pronounced in deprivation in housing, in transport and in durables (column 1). In the separate estimations (columns 2-5), calculated deprivation has the expected positive and significant relationship with perceived deprivation. The magnitude of the coefficient in each of the visible wealth dimensions 
is similar to the magnitude of the coefficient of deprivation in income. This shows that all dimensions of visible wealth are relevant, with no single dimension driving the results.

Another concern is the selection of visible wealth items. As we do not have self-reported information on the visibility of each item, we selected variables that are expected to be mostly visible within a village or town. The selection however might give a distorted picture of the visible wealth of a household. On the one hand, the included variables might only partly be visible or not visible at all. On the other hand, might have missed some information on visible wealth which is not at all reported in the survey. Due to the limited availability of information on the visibility of items, we cannot fully address this concern. It should be kept in mind that our result relies on a selection of variables based on the limited information available in a standard socio-economic household survey. Depending on whether the selection of visible wealth items covers too much or too little from the true visible wealth of the households, the finding under- or overestimates the true effect of visible wealth on deprivation.

Another concern with the composite indicator relates to the principal component weights. To check how the choice of PCA weights within each dimension affect the results, we run estimations using equal weights for all items within a dimension (see table 5). In general, the results stay in line with our finding. In the joint regression, deprivation in visible wealth remains significantly more important than income (column 1). Also in the regressions using the disaggregated variables of visible wealth, the influence of visible wealth is mostly large and significant. Merely the influence of livestock becomes small and insignificant (column 5).

Furthermore, we are concerned that the PCA weights do not sufficiently take account for the structural differences in the sample. Taking common weights for the whole sample assumes that all people in the sample value visible assets and goods in the same way. This might not be a reasonable assumption, in particular when looking at the structural differences between urban and rural households. An extreme example here is livestock which is considered to be an indicator of wealth in the countryside, while it is a sign of being poor in the cities. Therefore we calculate principal component weights separately for villagers and town dwellers and run the estimations (see table 6). The results from this exercise are again in line with our finding.

Another concern is related to the method of calculating the objective deprivation measures. While we chose Yitzhaki deprivation measures as they allow us to take account of individual comparisons, the economic literature often follows more general approaches e.g. by taking the mean or the geometric mean of the comparison group as a measure of deprivation. Both are simple measures which refer to one point of the distribution; the geometric mean additionally takes loss aversion into account (Jasso and Wegener, 1997). As a robustness check, we calculate arithmetic and geometric means of income and visible wealth within each village and town in our 
sample (see table 7) 8 We find that the mean-based measures do not significanlty affect perceived deprivation, neither deprivation in visible wealth nor deprivation in income. It is rather the absolute levels of income and visible wealth which have a significant negative relationship with perceived deprivation. This shows that individual comparisons and other parts of the distribution (as considered in the Yitzhaki measures) play a role for feelings of deprivation. The mean-based measures of deprivation are not able to make any comparisons between deprivation in income and visible wealth.

A further source of concern is our proxy measure for the feeling of deprivation, the variable on perceived deprivation. It rests on the assumption that the respondents are willing to reveal their true feeling of deprivation and report a high deprivation category if they feel economically deprived compared to others in the town or village. We are particularly concerned by the large portion of respondents (25\%) who choose the middle category of perceived deprivation, which reflects neither relative deprivation nor relative satisfaction. Both respondents who are highly deprived and respondents who are not deprived at all in terms of the calculated measures, place themselves in the middle. These people might not want to reveal themselves as deprived or privileged implying a distorted picture on deprivation. To address this concern, we conduct different sensitivity checks. First, we restrict the sample to only individuals who give a clear answer on whether they feel deprived or not and exclude people who chose the middle category of subjective deprivation (see table 8, column 1). The relationship between deprivation in visible wealth and perceived deprivation is even more pronounced when excluding the middle category respondents, with no significant effect of deprivation in income. In addition, we check whether the results change when shifting the middle category respondents to the non-deprived (lower bound) or to the deprived (upper bound). In the lower bound scenario, we assume that all respondents of the middle category do not want to reveal themselves as better-off. In the upper bound scenario, we assume that the middle category respondents did not want to reveal their feelings of deprivation. Accordingly, we allocated the middle category respondents in the upper bound scenario to the deprived $\left(D_{i c}=6\right)$ and in the lower bound scenario to the non-deprived $\left(D_{i c}=4\right)$ and run separate regressions (see table 8, columns 2-3). In both boundary scenaries, the magnitude of the coefficient of deprivation in visible wealth remains large and significant. The coefficient of income is significantliy smaller and even insignificant in the upper bound scenario.

A more general concern is the outliers, in particular the extreme values reported in the $99 \%$ percentile in income. To check whether the results are robust to these outliers, we created measures of deprivation including only the households in the $99 \%$ percentile of income, asset and consumption. The results excluding the outliers do not deviate from the general findings (see table 9).

\footnotetext{
${ }^{8}$ As the mean-based measures only marginally include the own level of economic wealth, a person's income and the aggregated PCA score in visible wealth are included as additional controls in the estimations.
} 


\section{Conclusion}

Motivated by the theory on deprivation, we expect visible wealth to be more important than income for somebody's feeling of deprivation. To test this hypothesis, we use household data from Kyrgyzstan with information on perceived deprivation. After identifying a range of visible items and calculating an indicator of deprivation in visible wealth and in income, we evaluate the explanatory power of deprivation in visible wealth with that of deprivation in income on perceived subjective deprivation. We find deprivation in visible wealth has on average a 10 percentage points higher explanatory power on perceived deprivation than the standard measure of deprivation in income. The finding on the importance of deprivation in visible goods and assets for perceived deprivation is confirmed in a number of robustness and sensitivity checks.

Clearly, each of the choices on the visible wealth items, the scoring and the implicit weighting may be questioned. However, with this study, we neither want to propose a definite measure of visible wealth, nor do we want to claim full external validity or any causal relationship between the different deprivation measures. Rather, we shed light on the role of visible wealth for deprivation. This paper should be the starting point for further research on deprivation and its impacts on human well-being and behavior. First important steps would be to collect more detailed information on the visibility and values of goods and assets, on the relevant comparison group and perceived deprivation in different dimension of well-being. Furthermore, researchers should exploit the whole range of information on goods and assets available, when calculating deprivation measures based on empirical data.

\section{References}

Alpizar, F., F. Carlsson, and O. Johansson-Stenman (2005). How much do we care about absolute versus relative income and consumption? Journal of Economic Behavior \& Organization 56(3), 405-421.

Bhandari, P. (2004). Relative deprivation and migration in an agricultural setting of Nepal. Population and Environment 25(5), 475-499.

Biemer, P., R. Groves, L. Lyberg, N. Mathiowetz, and S. Sudman (Eds.) (2011). Measurement errors in surveys, Volume 173. Hoboken, New Jersey, US: John Wiley \& Sons.

Birrell, D. (1972). Relative deprivation as a factor in conflict in Northern Ireland. Sociological Review 20(3), 317-343.

Bossert, W., S. Chakravarty, and C. D'Ambrosio (2013). Multidimensional poverty and material deprivation with discrete data. Review of Income and Wealth 59(1), 29-43. 
Brück, T., D. Esenaliev, A. Kröger, A. Kudebayeva, B. Mirkasimov, and S. Steiner (2014). Household survey data for research on well-being and behavior in Central Asia. Journal of Comparative Economics (in press).

Clark, A. and C. Senik (2010). Who compares to whom? the anatomy of income comparisons in Europe. Economic Journal 120(544), 573-594.

D'Ambrosio, C. and J. Frick (2007). Income satisfaction and relative deprivation: An empirical link. Social Indicators Research $81(3), 497-519$.

D'Ambrosio, C. and J. Frick (2012). Individual wellbeing in a dynamic perspective. Economica $79(314), 284-302$.

Deaton, A. (2001). Relative deprivation, inequality, and mortality. Technical report, Number w8099, Cambridge, US: National Bureau of Economic Research.

Easterlin, R. (1995). Will raising the incomes of all increase the happiness of all? Journal of Economic Behavior \&5 Organization 27(1), 35-47.

Easterlin, R. (2001). Income and happiness: Towards a unified theory. Economic Journal 111(473), $465-484$.

Eibner, C. and W. Evans (2005). Relative deprivation, poor health habits, and mortality. Journal of Human Resources 40(3), 591-620.

Fafchamps, M. and F. Shilpi (2008). Subjective welfare, isolation, and relative consumption. Journal of Development Economics 86(1), 43-60.

Ferrer-i-Carbonell, A. (2005). Income and well-being: an empirical analysis of the comparison income effect. Journal of Public Economics 89(5), 997-1019.

Greene, W. (2010). Econometric Analysis (6th ed.). Englewood Cliffs, New Jersey, US: Prentice Hall.

Grimm, M., C. Guenard, and S. Mesple-Somps (2002). What has happened to the urban population in Côte d'Ivoire since the 1980s? An analysis of monetary poverty and deprivation over 15 years of household data. World Development 30(6), 1073-1095.

Jasso, G. and B. Wegener (1997). Methods for empirical justice analysis: Part 1 framework, models, and quantities. Social Justice Research 10(4), 393-430.

Kingdon, G. G. and J. Knight (2007). Community, comparisons and subjective well-being in a divided society. Journal of Economic Behavior \& Organization 64 (1), 69-90. 
Klasen, S. (2000). Measuring poverty and deprivation in South Africa. Review of Income and Wealth $46(1), 33-58$.

Knight, J., L. Song, and R. Gunatilaka (2009). Subjective well-being and its determinants in rural China. China Economic Review 20(4), 635-649.

Kolenikov, S. and G. Angeles (2004). The use of discrete data in PCA: theory, simulations, and applications to socioeconomic indices. Chapel Hill, North Carolina, US: Carolina Population Center, University of North Carolina.

Kolenikov, S. and G. Angeles (2009). Socioeconomic status measurement with discrete proxy variables: Is principal component analysis a reliable answer? Review of Income and Wealth 55(1), 128-165.

Kuhn, P., P. Kooreman, A. Soetevent, and A. Kapteyn (2011). The effects of lottery prizes on winners and their neighbors: Evidence from the Dutch postcode lottery. American Economic Review 101 (5), 2226-2247.

Linssen, R., L. van Kempen, and G. Kraaykamp (2011). Subjective well-being in rural india: The curse of conspicuous consumption. Social Indicators Research 101(1), 57-72.

Luttmer, E. (2005). Neighbors as negatives: Relative earnings and well-being. Quarterly Journal of Economics 120(3), 963-1002.

Macours, K. (2011). Increasing inequality and civil conflict in Nepal. Oxford Economic Papers $63(1), 1-26$.

Maddala, G. (1986). Limited-dependent and qualitative variables in econometrics. Number 3. Cambridge, UK: Cambridge University Press.

Mc Bride, M. (2010). Money, happiness, and aspirations: An experimental study. Journal of Economic Behavior 65 Organization 74 (3), 262-276.

O'Brien, T. and A. De Longis (1996). The interactional context of problem-, emotion-, and relationship-focused coping: The role of the Big Five Personality Factors. Journal of Personality $64(4), 775-813$.

Permanyer, I. (2014). Assessing individuals' deprivation in a multidimensional framework. Journal of Development Economics 109, 1-16.

Runciman, W. (1966). Relative deprivation \& social justice: a study of attitudes to social inequality in twentieth-century England. London, UK: Routledge Kegan Paul. 
Stark, O. (1984). Rural-to-urban migration in LDCs: a relative deprivation approach. Economic Development and Cultural Change, 475-486.

Stark, O. and E. Taylor (1991). Migration incentives, migration types: The role of relative deprivation. Economic Journal, 1163-1178.

Van Praag, B., A. Hagenaars, and W. van Eck (1983). The influence of classification and observation errors on the measurement of income inequality. Econometrica: Journal of the Econometric Society, 1093-1108.

Yitzhaki, S. (1979). Relative deprivation and the Gini coefficient. Quarterly Journal of Economics, 321-324. 
Table 1: Visible asset items and goods

\begin{tabular}{|c|c|c|c|}
\hline & mean & sd & $\mathrm{N}$ \\
\hline \multicolumn{4}{|l|}{ housing (values in Kyrgyz Som, KGS) } \\
\hline another house or apartment & $28,056.26$ & $196,858.63$ & 2,859 \\
\hline $\begin{array}{l}\text { means of transport (values in } K G S \text { ) } \\
\text { motorcycle, scooter } \\
\text { car, minibus } \\
\text { tractor, truck }\end{array}$ & $\begin{array}{r}156.26 \\
62,309.70 \\
12,166.37\end{array}$ & $\begin{array}{r}2,588.94 \\
289,665.92 \\
102,035.02\end{array}$ & $\begin{array}{l}2,859 \\
2,859 \\
2,859\end{array}$ \\
\hline $\begin{array}{l}\text { livestock (numbers) } \\
\text { cow, bull } \\
\text { sheep, goat } \\
\text { horse } \\
\text { pig } \\
\text { chicken }\end{array}$ & $\begin{array}{l}1.15 \\
4.47 \\
0.19 \\
0.04 \\
4.59\end{array}$ & $\begin{array}{r}1.86 \\
12.91 \\
0.89 \\
0.52 \\
9.09\end{array}$ & $\begin{array}{l}2,859 \\
2,859 \\
2,859 \\
2,859 \\
2,859\end{array}$ \\
\hline \multicolumn{4}{|l|}{ durables (numbers) } \\
\hline electric stove & 0.71 & 0.46 & 2,859 \\
\hline microwave & 0.28 & 0.45 & 2,859 \\
\hline air conditioner & 0.04 & 0.21 & 2,859 \\
\hline sewing machine & 0.54 & 0.50 & 2,859 \\
\hline washing machine (automatic) & 0.19 & 0.40 & 2,859 \\
\hline vacuum cleaner & 0.52 & 0.50 & 2,859 \\
\hline sofa & 0.96 & 0.58 & 2,859 \\
\hline wardrobe & 1.17 & 0.68 & 2,859 \\
\hline bed & 1.20 & 1.11 & 2,859 \\
\hline kitchen furniture & 0.29 & 0.46 & 2,859 \\
\hline radios & 0.14 & 0.35 & 2,859 \\
\hline music systems & 0.12 & 0.33 & 2,859 \\
\hline television & 1.16 & 0.49 & 2,859 \\
\hline video player & 0.81 & 0.46 & 2,859 \\
\hline video camera & 0.03 & 0.18 & 2,859 \\
\hline photo camera & 0.05 & 0.23 & 2,859 \\
\hline photo camera (digital) & 0.07 & 0.27 & 2,859 \\
\hline computer & 0.10 & 0.32 & 2,859 \\
\hline satellite dish & 0.18 & 0.39 & 2,859 \\
\hline mobile phone & 1.54 & 0.92 & 2,859 \\
\hline \multicolumn{4}{|l|}{ expenditures (values in KGS) } \\
\hline entertainment, recreation, eating out & 309.50 & 627.24 & 2,861 \\
\hline internet, cable tv, communication & 331.25 & 355.87 & 2,861 \\
\hline celebration, funerals, rituals & 613.85 & $1,353.04$ & 2,861 \\
\hline education expenses & 191.62 & 646.32 & 2,861 \\
\hline clothing and shoes & 876.88 & 790.99 & 2,861 \\
\hline furniture and other interiors & 129.12 & 590.41 & 2,861 \\
\hline other durable goods & 120.09 & $1,203.47$ & 2,861 \\
\hline
\end{tabular}

Data source: LIK 2011. 
Table 2: Summary statistics

\begin{tabular}{|c|c|c|c|c|c|}
\hline & mean & sd & $\min$ & $\max$ & $\mathrm{N}$ \\
\hline \multicolumn{6}{|l|}{ deprivation measures: } \\
\hline perceived deprivation & 0.41 & 0.22 & 0 & 1 & 2,824 \\
\hline deprivation in income & 0.43 & 0.30 & 0 & 1 & 2,855 \\
\hline deprivation in visible wealth (pca wt.) & 0.49 & 0.20 & 0 & 1 & 2,863 \\
\hline \multicolumn{6}{|l|}{ individual-specific characteristics: } \\
\hline sex (dummy, $1=$ male, $0=$ female $)$ & 0.71 & 0.45 & 0 & 1 & 2,863 \\
\hline age & 51.23 & 14.15 & 16 & 99 & 2,863 \\
\hline married (dummy) & 0.71 & 0.46 & 0 & 1 & 2,863 \\
\hline Kyrgyz (dummy) & 0.67 & 0.47 & 0 & 1 & 2,863 \\
\hline born in this city/village & 0.76 & 0.43 & 0 & 1 & 2,858 \\
\hline education level & 4.77 & 1.44 & 1 & 7 & 2,858 \\
\hline general satisfaction with life & 6.59 & 2.27 & 0 & 10 & 2,854 \\
\hline openess & 3.34 & 0.78 & 1 & 5 & 2,646 \\
\hline conscientiousness & 3.86 & 0.76 & 1 & 5 & 2,646 \\
\hline extroversion & 2.49 & 0.97 & 1 & 5 & 2,646 \\
\hline agreeableness & 3.71 & 0.69 & 1 & 5 & 2,646 \\
\hline neuroticism & 2.42 & 0.63 & 1 & 5 & 2,646 \\
\hline \multicolumn{6}{|l|}{ community-specific characteristics: } \\
\hline region (dummy, $1=$ rural, $0=$ urban) & 0.58 & 0.49 & 0 & 1 & 2,863 \\
\hline Issyk-Kul oblast (dummy) & 0.09 & 0.29 & 0 & 1 & 2,863 \\
\hline Djalal-Abad oblast (dummy) & 0.16 & 0.37 & 0 & 1 & 2,863 \\
\hline Naryn oblast (dummy) & 0.04 & 0.21 & 0 & 1 & 2,863 \\
\hline Batken oblast (dummy) & 0.08 & 0.27 & 0 & 1 & 2,863 \\
\hline Osh oblast (dummy) & 0.17 & 0.37 & 0 & 1 & 2,863 \\
\hline Talas oblast (dummy) & 0.04 & 0.20 & 0 & 1 & 2,863 \\
\hline Chui oblast (dummy) & 0.17 & 0.37 & 0 & 1 & 2,863 \\
\hline Bishkek oblast (dummy) & 0.20 & 0.40 & 0 & 1 & 2,863 \\
\hline Osh oblast (dummy) & 0.04 & 0.21 & 0 & 1 & 2,863 \\
\hline
\end{tabular}

Data sources: LIK 2011 and LIK 2012 (character traits). 


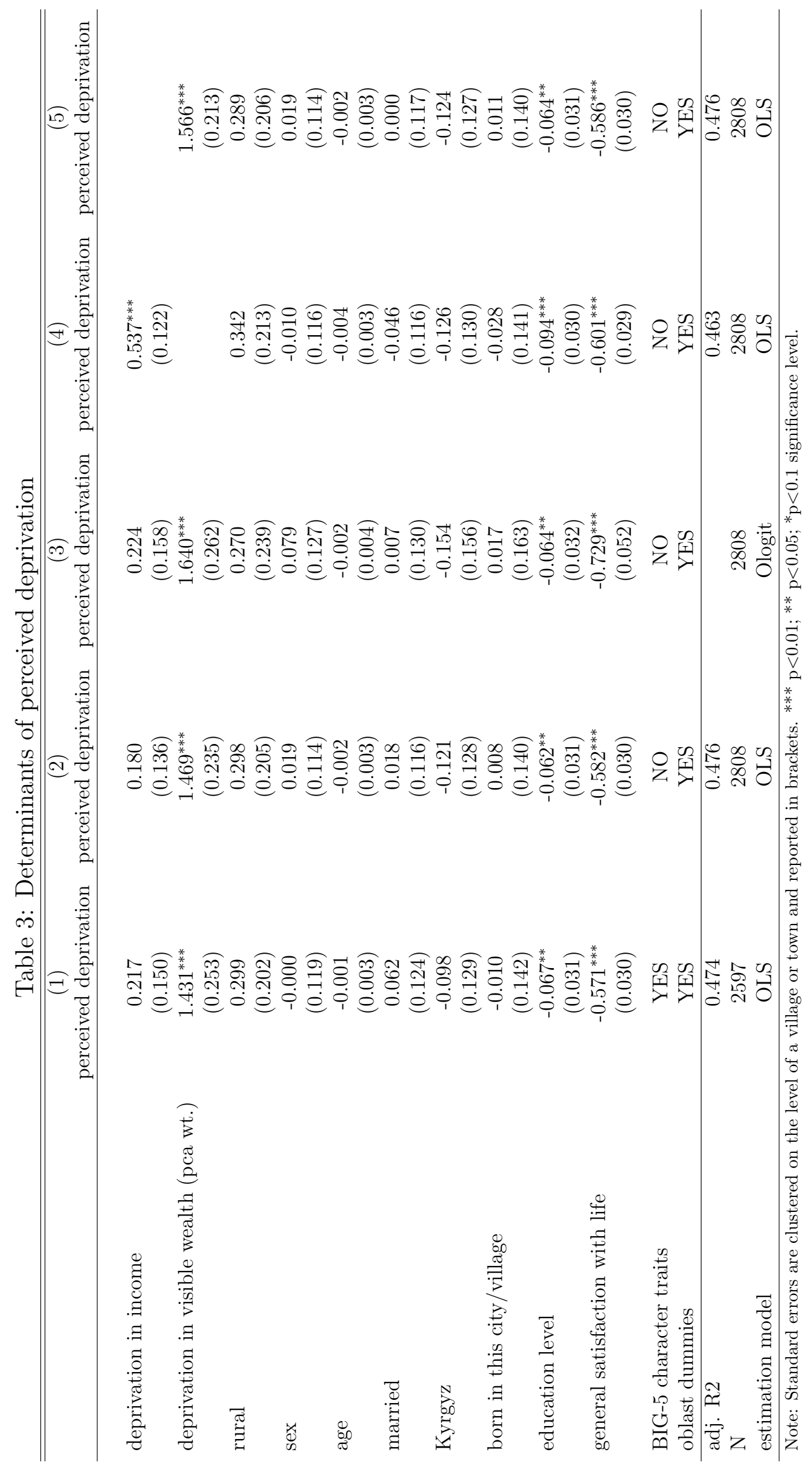




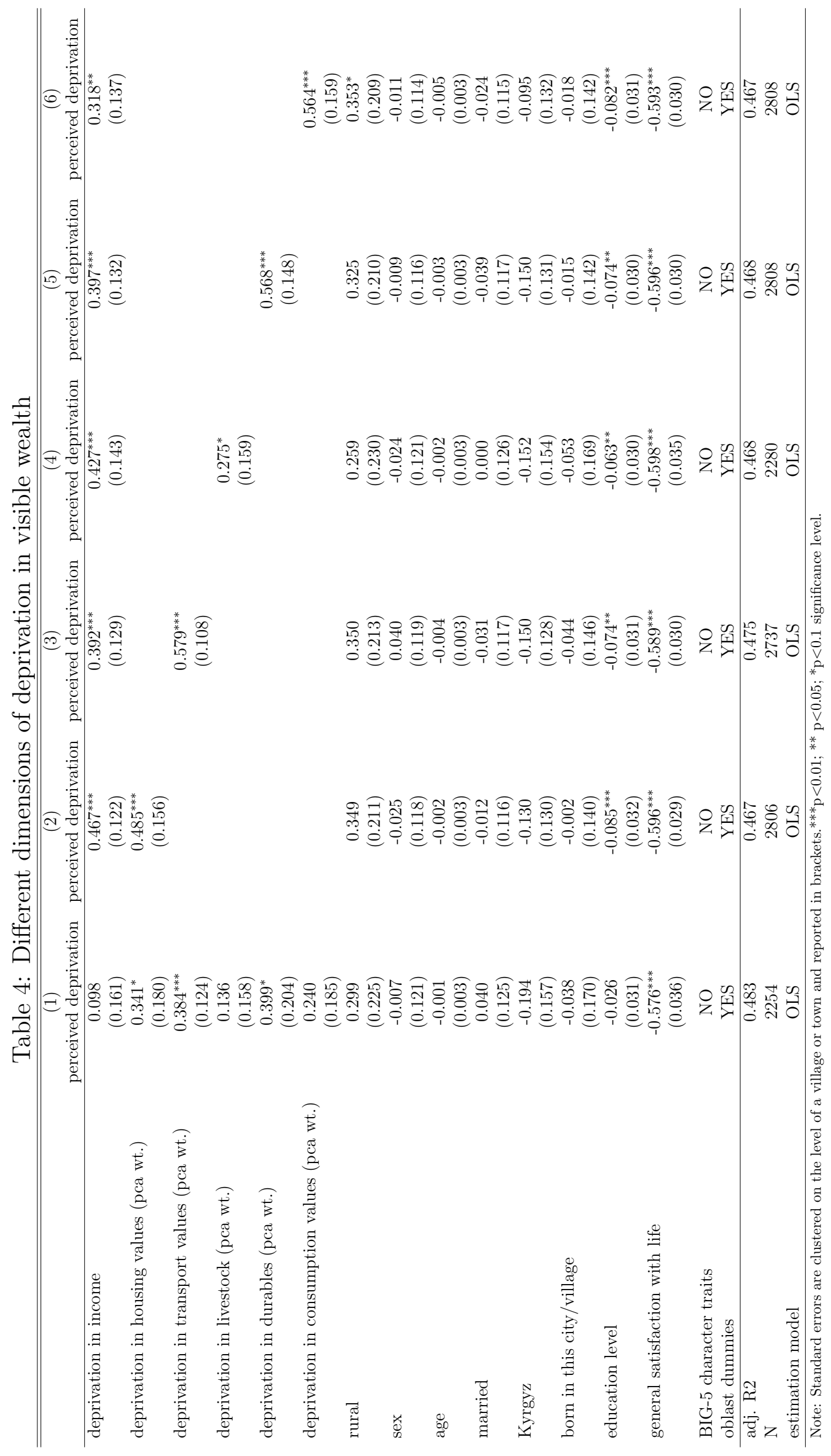




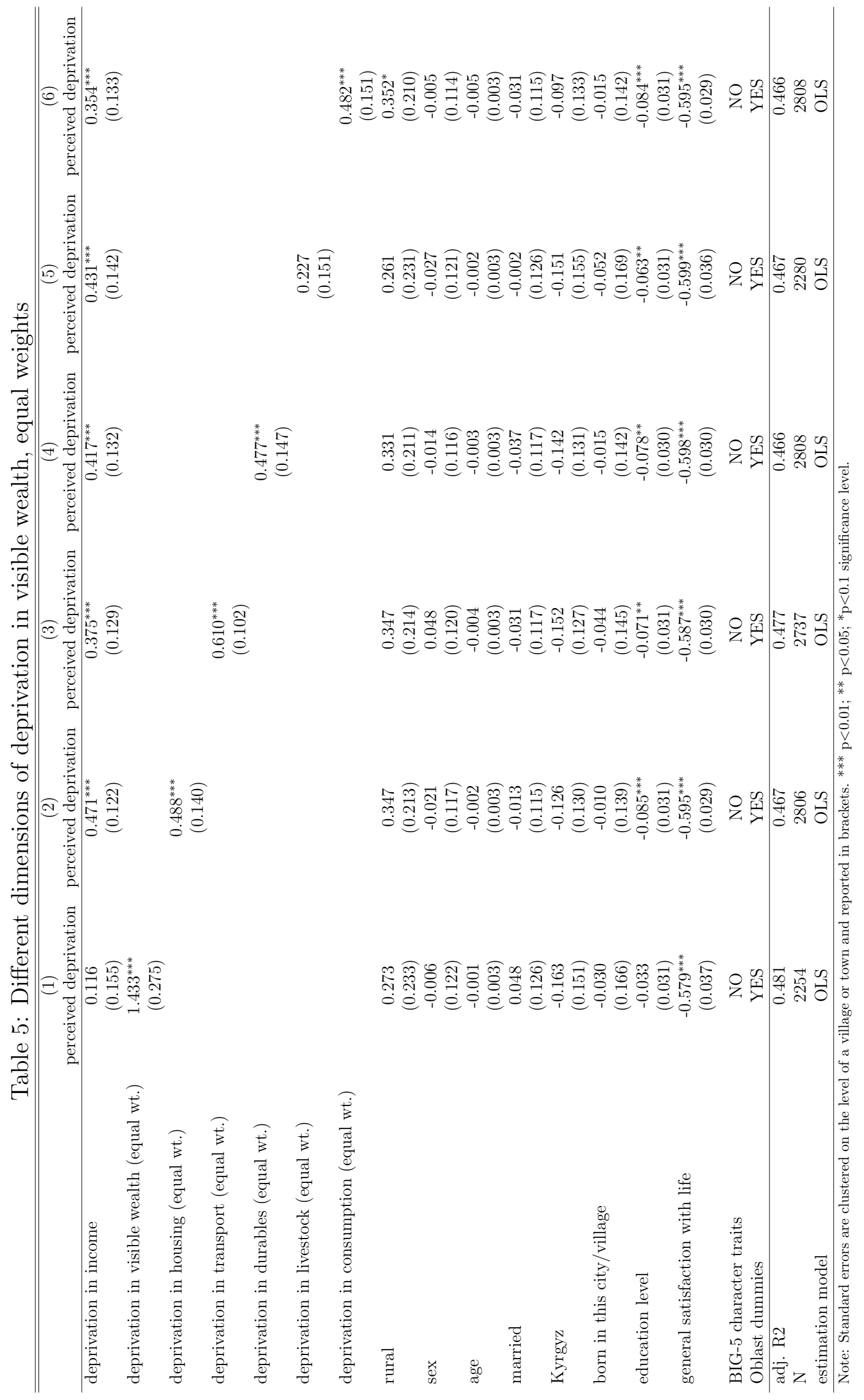


Table 6: Deprivation in visible wealth, separate weights for rural and urban

\begin{tabular}{|c|c|c|c|}
\hline & $\begin{array}{c}(1) \\
\text { perceived deprivation }\end{array}$ & $\begin{array}{c}\text { (2) } \\
\text { perceived deprivation }\end{array}$ & $\begin{array}{c}(3) \\
\text { perceived deprivation }\end{array}$ \\
\hline deprivation in income & $\begin{array}{c}0.196 \\
(0.135)\end{array}$ & $\begin{array}{c}0.537^{* * *} \\
(0.122)\end{array}$ & \\
\hline $\begin{array}{l}\text { deprivation in visible wealth } \\
\text { (pca wt., by location) }\end{array}$ & $\begin{array}{l}1.418^{* * *} \\
(0.241)\end{array}$ & & $\begin{array}{c}1.525^{* * *} \\
(0.220)\end{array}$ \\
\hline rural & $\begin{array}{c}0.276 \\
(0.204)\end{array}$ & $\begin{array}{c}0.342 \\
(0.213)\end{array}$ & $\begin{array}{c}0.265 \\
(0.204)\end{array}$ \\
\hline sex & $\begin{array}{c}0.014 \\
(0.114)\end{array}$ & $\begin{array}{l}-0.010 \\
(0.116)\end{array}$ & $\begin{array}{c}0.014 \\
(0.114)\end{array}$ \\
\hline age & $\begin{array}{l}-0.002 \\
(0.003)\end{array}$ & $\begin{array}{l}-0.004 \\
(0.003)\end{array}$ & $\begin{array}{l}-0.002 \\
(0.003)\end{array}$ \\
\hline married & $\begin{array}{c}0.019 \\
(0.117)\end{array}$ & $\begin{array}{l}-0.046 \\
(0.116)\end{array}$ & $\begin{array}{l}-0.001 \\
(0.118)\end{array}$ \\
\hline Kyrgyz & $\begin{array}{l}-0.122 \\
(0.128)\end{array}$ & $\begin{array}{l}-0.126 \\
(0.130)\end{array}$ & $\begin{array}{l}-0.126 \\
(0.127)\end{array}$ \\
\hline born in this city/village & $\begin{array}{l}0.005 \\
(0.139)\end{array}$ & $\begin{array}{l}-0.028 \\
(0.141)\end{array}$ & $\begin{array}{l}0.008 \\
(0.139)\end{array}$ \\
\hline education level & $\begin{array}{c}-0.065^{* *} \\
(0.031)\end{array}$ & $\begin{array}{c}-0.094^{* * *} \\
(0.030)\end{array}$ & $\begin{array}{c}-0.066^{* *} \\
(0.031)\end{array}$ \\
\hline general satisfaction with life & $\begin{array}{c}-0.582^{* * *} \\
(0.030)\end{array}$ & $\begin{array}{c}-0.601^{* * *} \\
(0.029)\end{array}$ & $\begin{array}{l}-0.586^{* * *} \\
(0.030)\end{array}$ \\
\hline BIG-5 character traits & $\mathrm{NO}$ & NO & $\mathrm{NO}$ \\
\hline oblast dummies & YES & YES & YES \\
\hline adj. R2 & 0.475 & 0.463 & 0.475 \\
\hline $\mathrm{N}$ & 2808 & 2808 & 2808 \\
\hline estimation model & OLS & OLS & OLS \\
\hline
\end{tabular}


Table 7: Mean-based deprivation measures

\begin{tabular}{|c|c|c|}
\hline & $\begin{array}{c}(1) \\
\text { perceived deprivation }\end{array}$ & $\begin{array}{c}(2) \\
\text { perceived deprivation }\end{array}$ \\
\hline mean income (log) & $\begin{array}{c}0.394 \\
(0.277)\end{array}$ & \\
\hline geometric mean income (log) & & $\begin{array}{l}0.346 \\
(0.240)\end{array}$ \\
\hline income $(\log )$ & $\begin{array}{c}-0.150^{* *} \\
(0.060)\end{array}$ & $\begin{array}{c}-0.135^{* *} \\
(0.062)\end{array}$ \\
\hline mean visible wealth (pca score) & $\begin{array}{l}-0.039 \\
(0.149)\end{array}$ & \\
\hline geometric mean visible wealth (pca score) & & $\begin{array}{c}0.324 \\
(0.229)\end{array}$ \\
\hline visible wealth (pca score) & $\begin{array}{c}-0.183^{* * *} \\
(0.038)\end{array}$ & $\begin{array}{c}-0.217^{* * *} \\
(0.044)\end{array}$ \\
\hline rural & $\begin{array}{c}0.282 \\
(0.203)\end{array}$ & $\begin{array}{c}0.310 \\
(0.210)\end{array}$ \\
\hline sex & $\begin{array}{l}-0.003 \\
(0.116)\end{array}$ & $\begin{array}{c}0.004 \\
(0.119)\end{array}$ \\
\hline age & $\begin{array}{l}-0.002 \\
(0.003)\end{array}$ & $\begin{array}{l}-0.002 \\
(0.003)\end{array}$ \\
\hline married & $\begin{array}{l}-0.016 \\
(0.117)\end{array}$ & $\begin{array}{l}-0.047 \\
(0.120)\end{array}$ \\
\hline Kyrgyz & $\begin{array}{l}-0.112 \\
(0.128)\end{array}$ & $\begin{array}{l}-0.118 \\
(0.130)\end{array}$ \\
\hline born in this city/village & $\begin{array}{c}-0.011 \\
(0.137)\end{array}$ & $\begin{array}{l}0.005 \\
(0.142)\end{array}$ \\
\hline education level & $\begin{array}{c}-0.078^{* *} \\
(0.031)\end{array}$ & $\begin{array}{c}-0.070^{* *} \\
(0.032)\end{array}$ \\
\hline general satisfaction with life & $\begin{array}{c}-0.595^{* * *} \\
(0.030)\end{array}$ & $\begin{array}{c}-0.592^{* * *} \\
(0.030)\end{array}$ \\
\hline $\begin{array}{l}\text { BIG-5 character traits } \\
\text { oblast dummies }\end{array}$ & $\begin{array}{l}\text { NO } \\
\text { YES }\end{array}$ & $\begin{array}{l}\text { NO } \\
\text { YES }\end{array}$ \\
\hline $\begin{array}{l}\text { adj. R2 } \\
\mathrm{N} \\
\text { estimation model }\end{array}$ & $\begin{array}{l}0.469 \\
2808 \\
\text { OLS }\end{array}$ & $\begin{array}{l}0.465 \\
2760 \\
\text { OLS }\end{array}$ \\
\hline
\end{tabular}

Table 8: Sensitivity analysis on the middle category respondents

\begin{tabular}{|c|c|c|c|}
\hline & $\begin{array}{c}\text { (1) } \\
\text { perceived deprivation }\end{array}$ & $\begin{array}{c}\text { (2) } \\
\text { perceived deprivation (upper bound) }\end{array}$ & $\begin{array}{c}\text { (3) } \\
\text { perceived deprivation (lower bound) }\end{array}$ \\
\hline \multirow[t]{2}{*}{ deprivation in income } & 0.122 & 0.126 & $0.234^{*}$ \\
\hline & $(0.154)$ & $(0.148)$ & $(0.131)$ \\
\hline \multirow[t]{2}{*}{ deprivation in visible wealth (pca wt.) } & $1.723^{* * *}$ & $1.538^{* * *}$ & $1.400^{* * *}$ \\
\hline & $(0.265)$ & $(0.258)$ & $(0.224)$ \\
\hline \multirow[t]{2}{*}{ rural } & 0.330 & 0.259 & $0.338^{*}$ \\
\hline & $(0.210)$ & $(0.240)$ & $(0.183)$ \\
\hline \multirow[t]{2}{*}{$\operatorname{sex}$} & -0.007 & 0.031 & 0.007 \\
\hline & $(0.143)$ & $(0.117)$ & $(0.117)$ \\
\hline \multirow[t]{2}{*}{ age } & -0.004 & -0.003 & -0.001 \\
\hline & $(0.004)$ & $(0.003)$ & $(0.003)$ \\
\hline \multirow[t]{2}{*}{ married } & -0.011 & 0.049 & -0.013 \\
\hline & $(0.152)$ & $(0.116)$ & $(0.122)$ \\
\hline \multirow[t]{2}{*}{ Kyrgyz } & -0.120 & -0.144 & -0.098 \\
\hline & $(0.140)$ & $(0.145)$ & $(0.117)$ \\
\hline \multirow[t]{2}{*}{ born in this city/village } & -0.001 & 0.040 & -0.023 \\
\hline & $(0.162)$ & $(0.147)$ & $(0.138)$ \\
\hline \multirow[t]{2}{*}{ education level } & $-0.066^{*}$ & $-0.061^{*}$ & $-0.064^{* *}$ \\
\hline & $(0.035)$ & $(0.033)$ & $(0.030)$ \\
\hline \multirow[t]{2}{*}{ general satisfaction with life } & $-0.667^{* * *}$ & $-0.616^{* * *}$ & $-0.548^{* * *}$ \\
\hline & $(0.030)$ & $(0.033)$ & $(0.028)$ \\
\hline BIG-5 character traits & NO & NO & NO \\
\hline oblast dummies & YES & YES & YES \\
\hline adj. R2 & 0.544 & 0.459 & 0.460 \\
\hline $\mathrm{N}$ & 2090 & 2808 & 2808 \\
\hline estimation model & OLS & Logit & Logit \\
\hline
\end{tabular}


Table 9: Determinants of perceived deprivation, outliers excluded

\begin{tabular}{lccc}
\hline \hline & $(1)$ & $(2)$ & $(3)$ \\
& perceived deprivation & perceived deprivation & perceived deprivation \\
\hline deprivation in income, without outlier & 0.115 & $0.471^{* * *}$ & $\left(.566^{* * *}\right.$ \\
deprivation in visible wealth (pca wt.) & $(0.139)$ & $(0.125)$ & $(0.213)$ \\
& $1.509^{* * *}$ & & 0.289 \\
rural & $(0.240)$ & 0.331 & $(0.206)$ \\
& 0.288 & $(0.212)$ & 0.019 \\
sex & $(0.203)$ & -0.010 & $(0.114)$ \\
& 0.019 & $(0.116)$ & -0.002 \\
age & $(0.114)$ & -0.004 & $(0.003)$ \\
& -0.002 & $(0.003)$ & 0.000 \\
married & $(0.003)$ & -0.051 & $(0.117)$ \\
Kyrgyz & 0.016 & $(0.116)$ & -0.124 \\
born in this city/village & $(0.116)$ & -0.135 & $(0.127)$ \\
education level & -0.128 & $(0.129)$ & 0.011 \\
& $(0.128)$ & -0.037 & $(0.140)$ \\
general satisfaction with life & -0.001 & $(0.142)$ & $-0.064^{* *}$ \\
& $(0.141)$ & $-0.092^{* * *}$ & $(0.031)$ \\
BIG-5 character traits & $-0.060^{*}$ & $(0.031)$ & $-0.586^{* * *}$ \\
oblast dummies & $(0.031)$ & $-0.603^{* * *}$ & $(0.030)$ \\
\hline adj. R2 & $-0.583^{* * *}$ & $(0.029)$ & NO \\
N & $(0.030)$ & NO & YES \\
estimation model & NO & YES & 0.476 \\
Note: Standard errors are clustered on the level of a village or town and reported in brackets.*** p<0.01; ** p<0.05; * p $<0.1$ significance level.
\end{tabular}

Figure 1: Screeplot of different dimensions of visible wealth
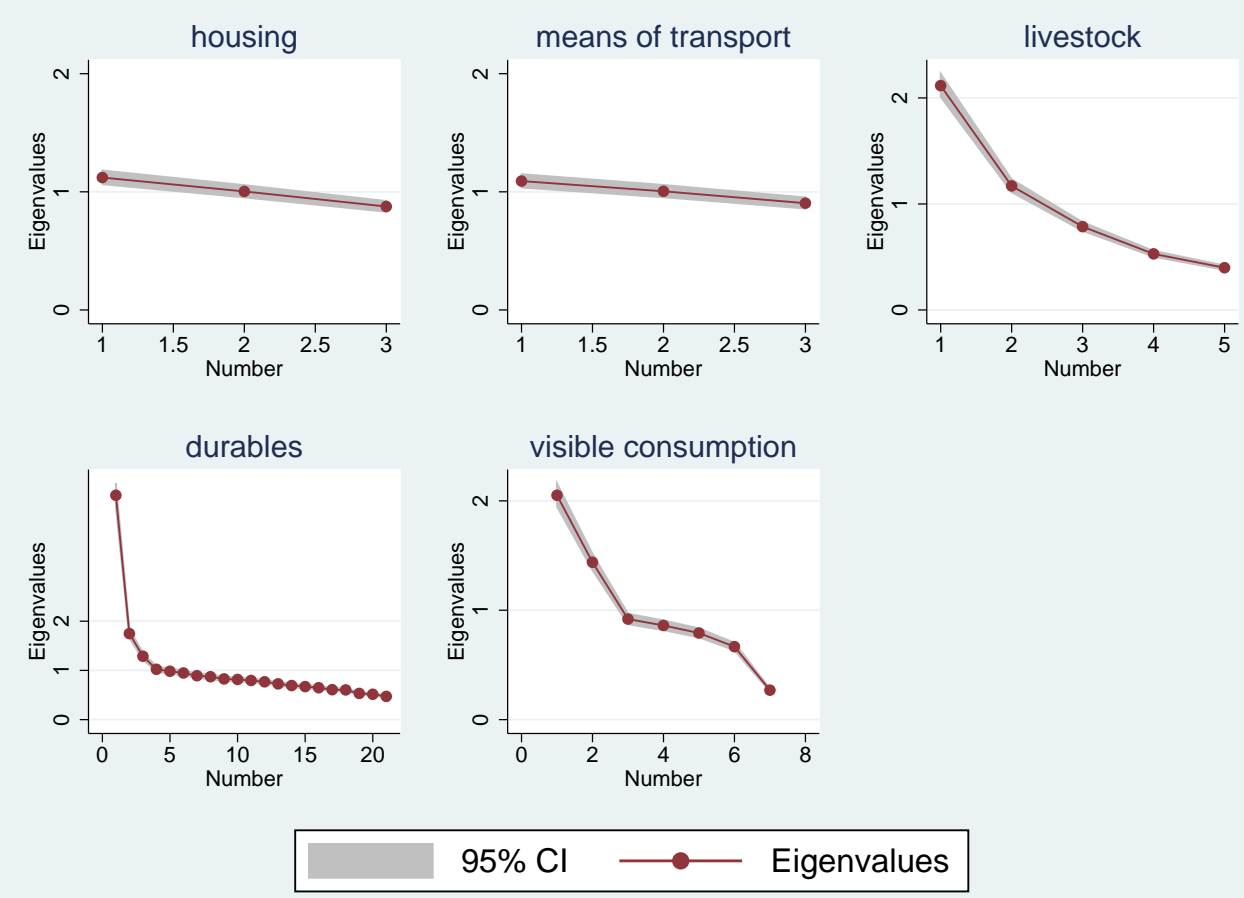

Note: Screeplots are based on the PCA within each of the different dimensions of visible wealth. 
Figure 2: Distribution of deprivation measures

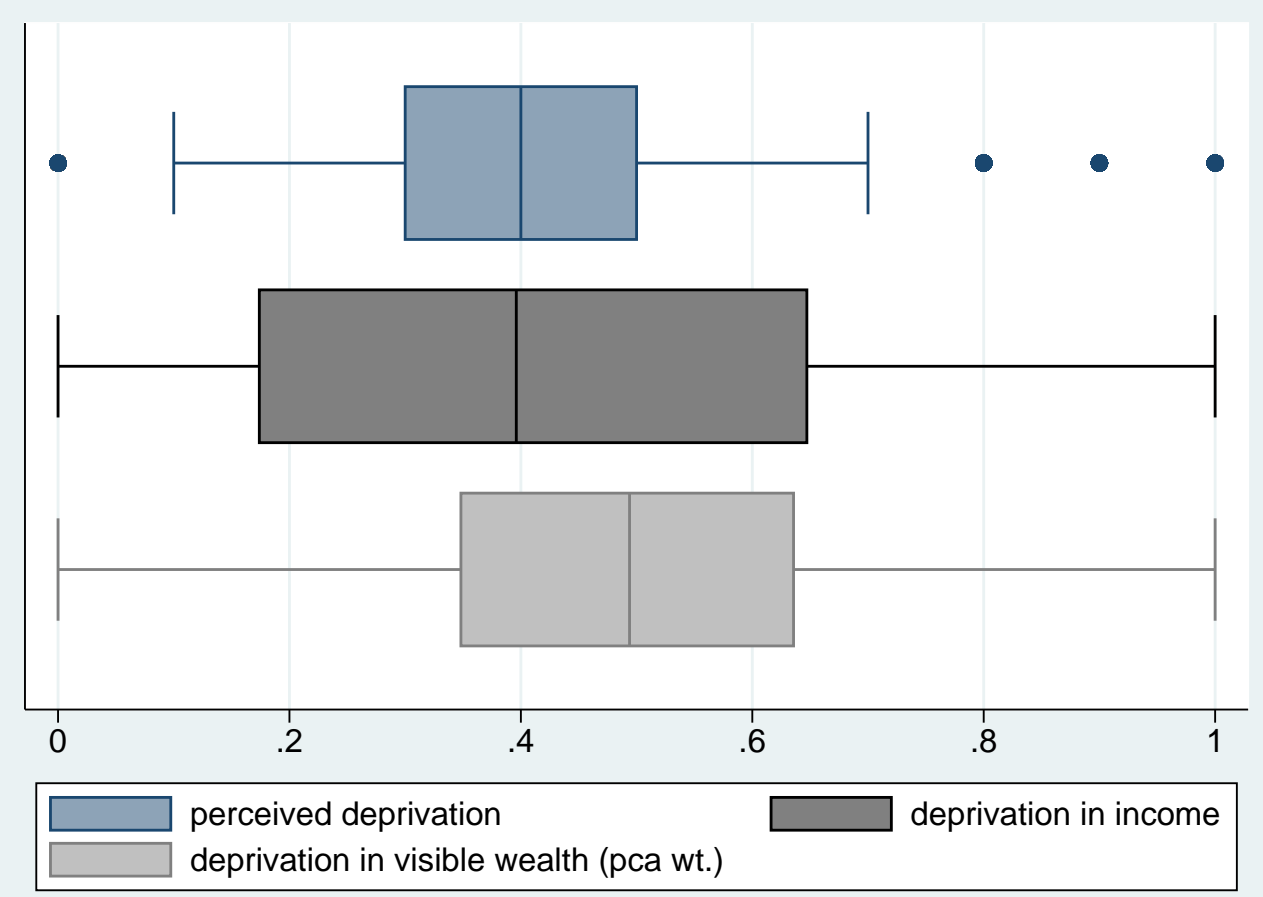

Note: In this illustration, perceived deprivation is normalized to a range from zero and one to compare it with deprivation visible wealth and deprivation in income.

Figure 3: Predicted probabilities of high perceived deprivation

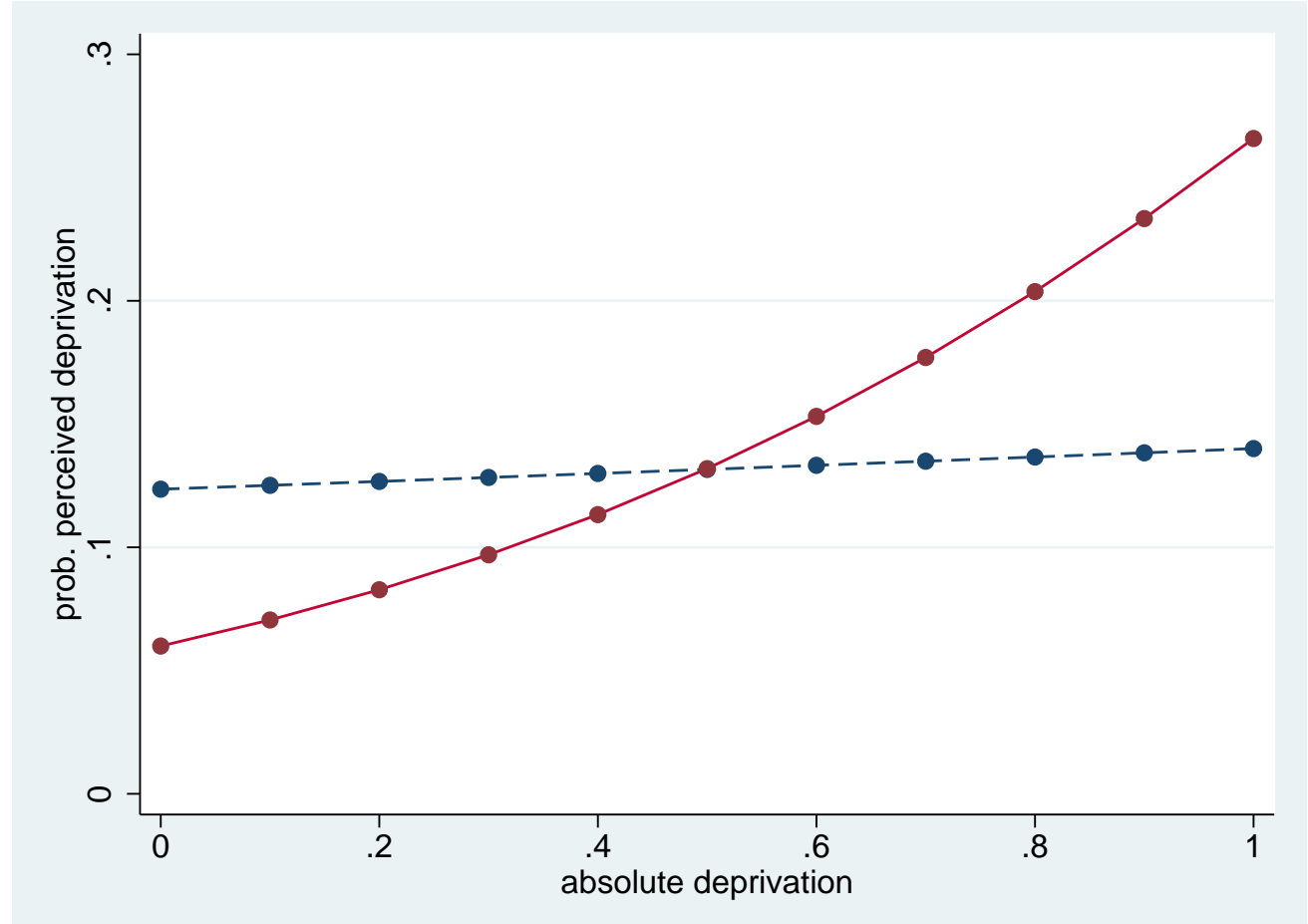

Note: Predicted probabilities of feeling deprived at different levels of actual deprivation in visible wealth (red line) and in income (blue, dashed line). Predictions are based on the ordered logit estimation in table 3 , column 3. 